\title{
Study on Low Hilly Cities Land Suitability Evaluation Method Based on Ecological Considerations-A Case Study of Longfeng New Town in Sichuan
}

\author{
Bin Cheng, Haifeng Lan, Weiwei Wu \\ School of Civil Engineering and Architecture, Southwest University of Science and Technology, Mianyang, China \\ Email: lanhaifeng@mails.swust.edu.cn
}

How to cite this paper: Cheng, B., Lan, H.F. and Wu, W.W. (2018) Study on Low Hilly Cities Land Suitability Evaluation Method Based on Ecological Considerations-A Case Study of Longfeng New Town in Sichuan. Journal of Building Construction and Planning Research, 6, 41-51. https://doi.org/10.4236/jbcpr.2018.62003

Received: April 3, 2018

Accepted: June 2, 2018

Published: June 5, 2018

Copyright $\odot 2018$ by authors and Scientific Research Publishing Inc. This work is licensed under the Creative Commons Attribution International License (CC BY 4.0).

http://creativecommons.org/licenses/by/4.0/

\begin{abstract}
Attention to the development of low hilly cities increases, in order to guide their development towards efficient and ecological land use. This paper takes eco-safety into consideration in the future layout of land for construction, and incorporates ecological security factors into traditional methods of land suitability evaluation based on topographic conditions. Taking the Longfeng New Town in Suining City as an example, the GIS platform is used to superimpose various evaluation factors. The evaluation index system is determined using the combination of the Delphi Technique and AHP. The result of correcting traditional land suitability evaluation is obtained, which provides decision support for improving the scientificity of land use planning and layout.
\end{abstract}

\section{Keywords}

Ecological Considerations, Urban Land Use, Suitability Evaluation GIS

(Geographic Information System)

\section{Introduction}

Land suitability evaluation is the process of determining the suitability of a particular area of land [1]. Land suitability assessment has become an essential tool for spatial control planning and land development in urban and rural areas [2] [3] [4]. Early practice of land suitability evaluation methods was based on the knowledge of environmental science, analyzing various environmental factors, and demarcating environmentally sensitive areas with high degrees of naturalness [5]. The area of suitability is identified by overlay map analysis [6]. The 
natural environment which contributes to urban sustainable development provides citizens with fresh air, food, sports, recreation, safe shelter, and aesthetic and educational services [7]. The concept of landscape security emphasizes the continuity and completeness of maintaining and restoring landscape ecological processes and patterns, and provides theoretical guidance for the study of regional ecological patterns [8]. Ecological indicators play an important role in the process of constructing land suitability evaluation [9].

Against the background of the continuous development of engineering technology, the selection of urban land for development is becoming less and less restricted by natural conditions, such as topography and terrain. In low hilly cities, more and more hilly areas have been selected as urban development land [10]. Low hills areas are where land is rugged and rolling hills are below 500 meters, and the relative height is generally less than $200 \mathrm{~m}$ [11]. The complexity and diversity of the topography has created a unique urban landscape in low hilly cities. However, steep gradients, loose rock and soil, high rainfall and far runoff, often found in rivers and valleys of cities, cause floods, soil erosion, and valley erosion at the same time [12].

At present, although land suitability evaluation is very common in urban land. There is no consensus on how to scientifically develop hilly regions and scientifically plan the layout of hilly cities land [13]. China's hilly terrain is about $10 \%$ of the country's land area [14]. Due to its relatively low slope, low development and construction cost, low impact of geological disasters, and good natural landscape, the land of low hill area can be used reasonably as the urban construction land. This paper selects a typical low hilly city-Longfeng New Town, Suining as a case study. By integrating Longfeng's unique ecological factors into the land suitability evaluation, it uses the evaluation results to guide the development of the city in the direction of ecological, high-efficiency and more scientific land-use planning and layout.

\section{Methodology}

\subsection{Study Area}

Longfeng New Town, located in Suining City, in the southwest of Sichuan Province, China, has a total area of 2.23 square kilometers and is the southern gateway to the city of Suining. In recent years, the rapid economic development of Suining has increased the city's demand for land, and various infrastructure facilities. In order to disperse population and relieve the pressure in the city center, it was decided to set up a new city called Longfeng New Town to the south of Suining City. Longfeng New Town is located along the banks of the Quhe River in a hilly area (Figure 1). The city has a small hilly area with a relative height of about $120 \mathrm{~m}$. It is a typical low hilly city, within its boundary vegetation is abundant, green coverage is relatively high, and the ecological environment is good. It is an excellent example to study the suitable land use of low hilly cities. 


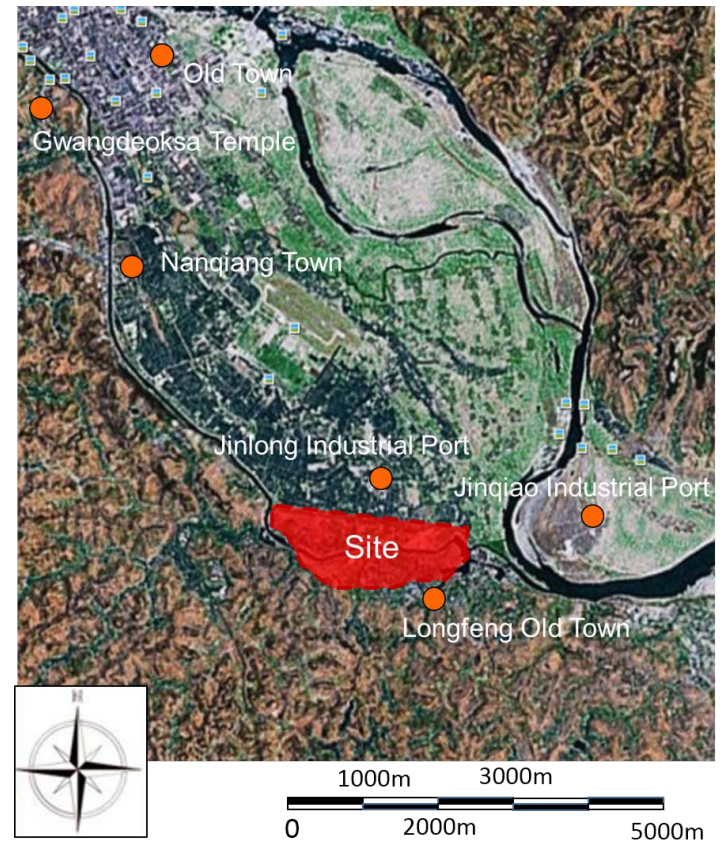

Figure 1. Study area.

\subsection{Technical Route}

Eco-considerations in land suitability evaluation methods for low hilly cities mainly include the selection of evaluation factors and the determination of the weight of indicators [15] [16]. Evaluation factors mainly include the consideration of topographic factors and ecological factors. The selection of evaluation factors is done by convening experts from various industries, using Delphi Technique, selecting factors according to the actual conditions of the site, and assessing the impact of relevant evaluation factors in each field on land suitability. The determination of the weight of indicators uses the AHP (Analytic Hierarchy Process) to compare the importance of and calculate the weights of the evaluation factors. According to the weight of the evaluation factor, GIS is used to superimpose the layers of each evaluation factor, from which the evaluation layer of land suitability can be obtained. The technology roadmap is shown in Figure 2.

\subsection{Evaluation Factor Selection and Classification}

The selection of evaluation factors and the determination of weights are key to the success of land suitability evaluation method based on ecological considerations [17]. The selection method for the evaluation factors is to select 21 experienced experts in urban planning and eco-environmental fields. They provided with information on the status quo of the research area through emails, so that they can select appropriate evaluation factors for suitable, comparative suitable, and unsuitable grading standards. Their opinions are then synthesized and fed back to them. This is repeated several times until they reach a relatively unanimous opinion. 


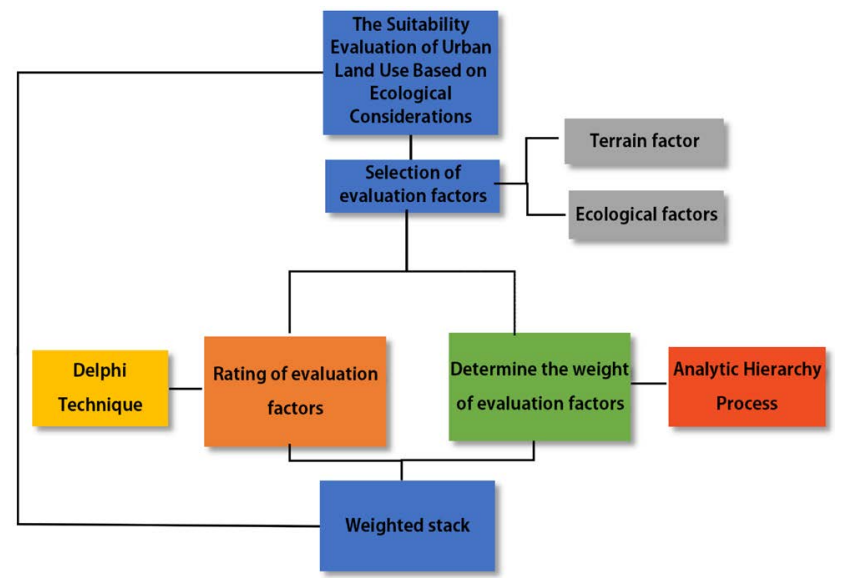

Figure 2. Technology roadmap.

\subsection{Weighting of Evaluation Indicators}

Determination of weight is an important step in comprehensive evaluation. The key to quantitative evaluation is to allocate the weight of each evaluation index rationally [17]. The method of combining AHP with Delphi technique is adopted. The specific operation steps are as follows.

1) Select expert

There should be about 21 experts who have practical experience and deep theoretical knowledge in the relevant fields of interest. The grades are scored according to the importance of the evaluation factors. The score table is shown in Table 1.

2) Initially determine weights

The experts use their actual experience and expertise to score the evaluation indicators, and then calculate the weights. The process should keep experts in various fields thinking and scoring independently. The calculation process of weight value is as follows.

Step 1: construct the judgment matrix.

$$
\begin{array}{cccccc} 
& C_{1} & C_{2} & C_{3} & \cdots & C_{n} \\
C_{1} & a_{11} & a_{12} & a_{13} & \cdots & a_{1 n} \\
C_{2} & a_{21} & a_{22} & a_{23} & \cdots & a_{2 n} \\
C_{3} & a_{31} & a_{32} & a_{33} & \cdots & a_{3 n} \\
\vdots & \vdots & \vdots & \vdots & \ddots & a_{4 n} \\
C_{n} & a_{n 1} & a_{n 2} & a_{n 3} & a_{n 4} & a_{n n}
\end{array}
$$

Step 2: calculate the eigenvectors.

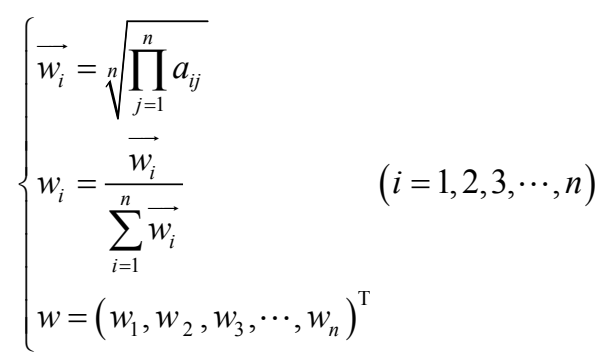


where, $\bar{w}_{i}$ is the geometric mean of each column of the construct matrix. $w_{i}$ is normalization of $\overline{w_{i}}$ vectors; $w$ is eigenvector of matrix.

Step 3: calculate the maximum characteristic root of the judgment matrix.

$$
\lambda_{\max }=\sum_{i=1}^{n} \frac{(A w)_{i}}{n w_{i}}
$$

where, $A$ is judgment matrix; $w$ is eigenvector of matrix; $\lambda_{\max }$ is maximum characteristic root of judgment matrix.

Step 4: consistency validation.

$$
\left\{\begin{array}{l}
C I=\frac{\lambda_{\max }-n}{n-1} \\
C R=\frac{C I}{R I}
\end{array}\right.
$$

where, $R I$ is the average random consistency index of, and can be found by the Table 2; $C I$ is Consistency Index the judgment matrix; $C R$ is Consistency Ration. If $C R$ is less than 0.1, the judgment matrix satisfies Consistency, the data is real and feasible. Otherwise, adjust the judgment matrix and recalculate.

3) Modify the weight value

The results of the evaluation of the experts are verified with consistency. The statistical verification method is adopted to calculate the value of mean and standard deviation. The experts correct the weights according to the determined value of mean and standard deviation.

4) Validate the verification weight

Repeat steps (3) and (4) above until the expert opinion are basically the same. The average value of the difference should not exceed 5\% - 10\%. The average value of each index is used as the weight of the index.

\subsection{Layer Overlay and Reclassification}

\section{1) Layer overlay}

The actual suitability state of the land on the layer is determined by the state of each cell in the layer [18]. There are three states of the cell, which can be assigned to suitability $=3$, comparative suitability $=2$, unsuitability $=1$. For weighting overlays for each layer, the computational formula is shown in (4). The layer overlay principle is shown in Figure 3.

$$
S=\sum_{1}^{n} X_{i} \cdot W_{i}
$$

where: $S$ stands for the value of land suitability; $X_{i}$ represents the ith evaluation factor; $W_{i}$ is the ith weight of evaluation factor; $\mathrm{n}$ is the number of evaluation factors.

2) Reclassification

After layer superposition, each cell will get new values. The Reclassify function of spatial Analyst in ArcGIS is used to reclassify by the following criteria. A cell's value is $2-3$ representing suitability, $1-2$ representing comparative suitability, 0 -1 representing unsuitability. 
Table 1. Analytic hierarchy scale meaning table.

\begin{tabular}{|c|c|}
\hline Scaling & Meaning \\
\hline 1 & Indicates that two factors are equally important \\
\hline 3 & Indicates that two factors are slightly more important than another factor \\
\hline 5 & Indicates that two factors are significantly more important than another factor \\
\hline 7 & Indicates that two factors are more important than one factor than another \\
\hline 9 & It means that two factors are extreme important than the other \\
\hline $2,4,6,8$ & The median of the above two adjacent judgments \\
\hline Reciprocal & Factor $C_{i}$ and $C_{j}$ compare the judgment of $a_{i j}, a_{j i}=1 / a_{i j}$. \\
\hline
\end{tabular}

Table 2. Consistency index RI.

\begin{tabular}{|c|c|c|c|c|c|c|c|c|c|c|c|c|c|c|c|c|c|}
\hline \multicolumn{2}{|c|}{ No. } & \multicolumn{2}{|c|}{1} & \multicolumn{2}{|l|}{2} & 3 & \multicolumn{2}{|c|}{4} & \multicolumn{2}{|c|}{5} & \multicolumn{2}{|l|}{6} & 7 & \multicolumn{2}{|c|}{8} & \multicolumn{2}{|c|}{9} \\
\hline \multicolumn{2}{|c|}{ RI } & \multicolumn{2}{|c|}{0.00} & \multicolumn{2}{|c|}{0.00} & 0.58 & \multicolumn{2}{|c|}{0.90} & \multicolumn{2}{|c|}{1.12} & \multicolumn{2}{|l|}{1.24} & 1.32 & \multicolumn{2}{|c|}{1.41} & \multicolumn{2}{|c|}{1.45} \\
\hline 1 & 2 & 3 & 2 & \multirow{4}{*}{\multicolumn{2}{|c|}{$\times$}} & \multirow{4}{*}{+} & 2 & 3 & 3 & 2 & \multirow{4}{*}{$\times$} & \multirow{4}{*}{ b } & \multirow{4}{*}{$=$} & 2 & 3 & 3 & 2 \\
\hline 2 & 3 & 2 & 1 & & & & 1 & 2 & 3 & 1 & & & & 2 & 3 & 3 & 1 \\
\hline 2 & 3 & 2 & 1 & & & & 1 & 2 & 3 & 1 & & & & 2 & 3 & 3 & 1 \\
\hline 1 & 2 & 3 & 2 & & & & 2 & 3 & 3 & 2 & & & & 2 & 2 & 3 & 2 \\
\hline
\end{tabular}

Figure 3. Layer overlay principle diagram.

\section{Results}

\subsection{Evaluation Factor Selection and Rating Results}

According to the experts' comprehensive consideration of the actual construction of the site of Longfeng New Town, the elevation, slope, aspect, type of land cover, and risk of ground disasters are selected as evaluation factors. These indicators include the topographic conditions and ecological aspects of the land. The evaluation results of the evaluation factors are shown in Table 3. According to the rating results of the evaluation factors, ArcGIS software is used to analyze the evaluation factors. The analysis graphic of various assessment factors is shown in Figure 4.

\subsection{Weighting of Evaluation Factors}

According to the results of multiple rounds of scoring by experts in various fields, the weights of the final assessment factors obtained from the consolidation analysis are shown in Table 4.

\subsection{Overlay Analysis and Reclassification Results Analysis}

The overlaying of the layers gives the final result that reflects the situation of land suitability of Longfeng New Town, as show in Figure 5. The results show that the suitable land for construction is distributed in areas where the terrain is 
gentle, and the location conditions and ecological conditions are relatively good. Construction is not suitable where land is mainly concentrated in areas with steep slopes, prone to geological disasters, and high ecological sensitivity. The
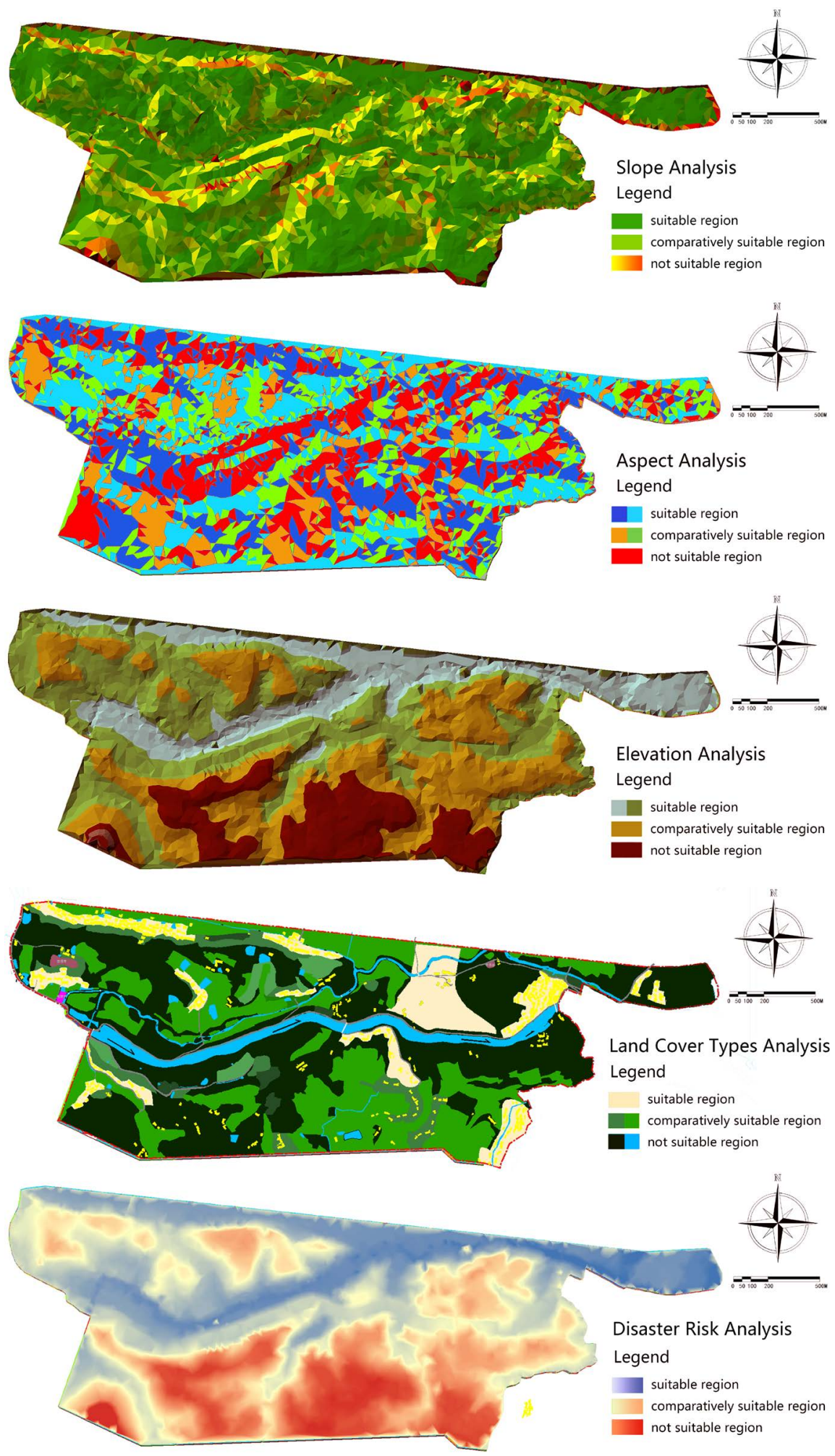

Figure 4. Evaluation factors land-use suitability classification diagram. 


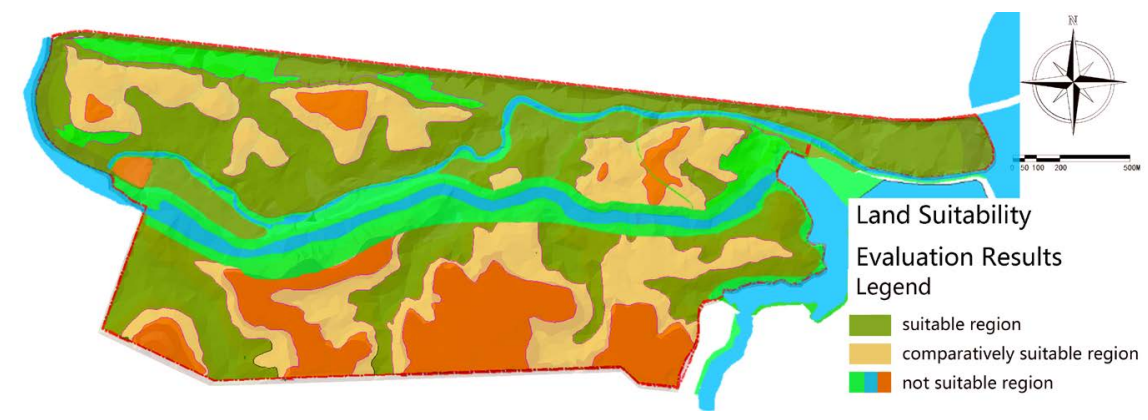

Figure 5. Evaluation results of land suitability.

Table 3. Evaluation factor rating list.

\begin{tabular}{ccc}
\hline Evaluation factor & Classification & Land suitability \\
\hline Slope -15 degrees & Suitable \\
$15-30$ degrees & Comparatively suitable \\
More than 30 degrees & Unsuitable \\
$262-290 \mathrm{~m}$ & suitable \\
$291-320 \mathrm{~m}$ & Comparatively suitable \\
Elevation & 320 - 380 m & Unsuitable \\
Aspect & South, southeast, southwest & suitable \\
& East, west, northwest, northeast & Comparatively suitable \\
& North & Unsuitable \\
Land cover type & Garden, wasteland, cultivated land & Comparatively suitable \\
& Water area, woodland & Unsuitable \\
Disaster risk & Little danger & suitable \\
& Less dangerous & Comparatively suitable \\
& More dangerous & Unsuitable \\
& &
\end{tabular}

Table 4. The weight of the evaluation factor.

\begin{tabular}{cccccc}
\hline Evaluation factor & Slope & Elevation & Aspect & Land cover type & Disaster risk \\
\hline Evaluation factor weight & 0.298 & 0.134 & 0.040 & 0.313 & 0.215 \\
\hline
\end{tabular}

comparatively suitable land for construction is exactly located between the first two. According to the analysis of ArcGIS software, the suitable land for construction area is $1.02 \mathrm{~km}^{2}$, accounting for $45.6 \%$ of the total land area. The comparatively suitable land for construction area is $0.50 \mathrm{~km}^{2}$, accounting for $22.3 \%$ of the total land area. The unsuitable land for construction area is $0.71 \mathrm{~km}^{2}$, accounting for $32.1 \%$ of the total land area.

In the process of urban land use planning of Longfeng New Town, make unsuitable construction land become an open space, after comprehensive consideration of suitability of land construction. Taking good mountain resources as a 
point of attraction for residential functions, the plan is to make use of the natural mountain on the south side as a city mountain park, and connect each residential groups in visual corridors. The land close to the water system and good land suitability is used as urban waterfront leisure land and first-class of residential land to improve the habitability of the city. The relatively suitable and less ecologically sensitive land will be used as the second-class residential land, where the volume ratio of the building is relatively high and a full range of living and service facilities should be provided to increase the city population capacity (Figure 6).

\section{Discussion}

In low hilly cities there are also some limitations on suitable land evaluation methods based on ecological considerations. First, the criteria for the classification of weight values and evaluation factors still depend on the subjective judgment of the expert group. Second, the selection of evaluation factors is limited by the basic data. Only ecological factors such as static vegetation, water areas, and mountains are considered, and some dynamic ecological factors such as habitats of animals and migration corridors are not considered and could not be fully reflected. Because of the inadequacies in the suitability evaluation method for land use, it is necessary to further develop relevant researches and improve and optimize it by introducing more technical methods so that it can guide the layout of urban land more scientifically and rationally.

\section{Conclusions}

The core of land suitability evaluation is to evaluate and establish an index system that meets the characteristics of the study area. This article combined the expertise of experts with the Delphi Technique and analytic hierarchy process (AHP). After initial feedback, the expert group made several rounds of selection

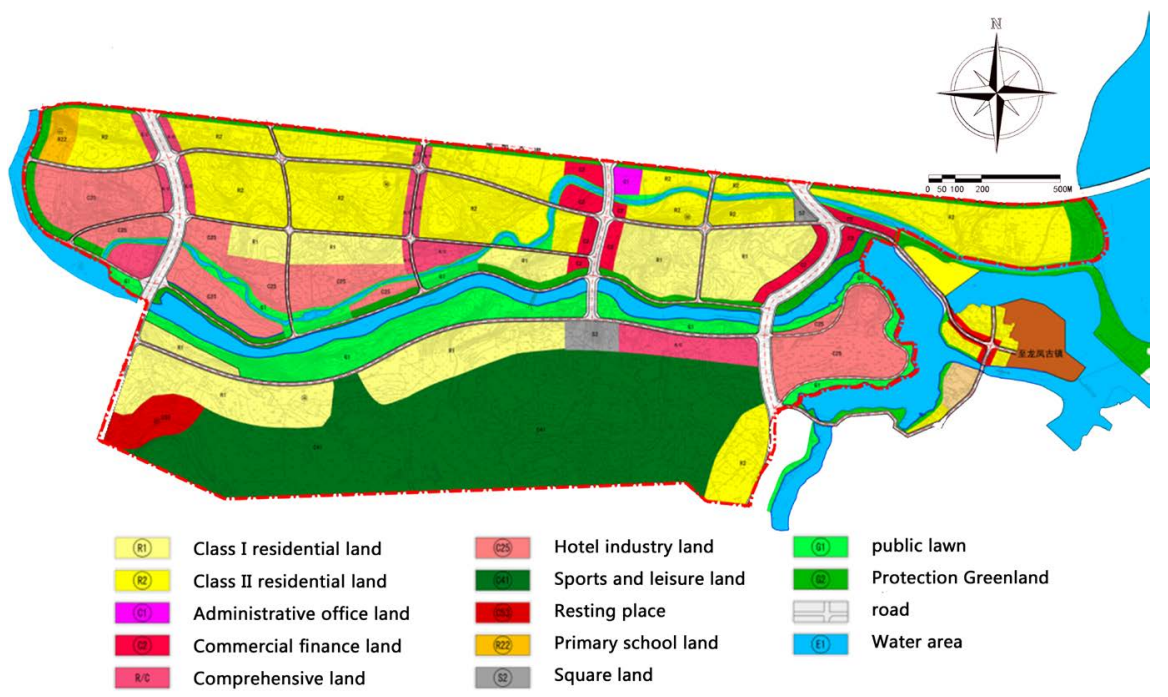

Figure 6. Land use planning of Longfeng New Town. 
of evaluation factors and corrections in the weight of evaluation indicators, and finally built a relatively consistent and credible evaluation index system. The evaluation index reflects the evaluation factors that represent the characteristics of the hilly region, such as vegetation cover types and geological hazards, etc.

The final land suitability evaluation result map is very effective in guiding the development and construction of low hilly cities. The land with strong land suitability is mainly located in the foothills, with low development cost and low ecological sensitivity. Consequently, it is more suitable for concentrated development. The land with comparative suitability is recommended to conserve topographic features and protect the original vegetation pattern. Here it is advisable to adopt a low-density, group-based development model to reflect regional characteristics. Unsuitable construction land is mainly distributed in high areas, with steep slopes, concentrated forest lands, and high ecological sensitivity. This kind of land is of great significance in maintaining biodiversity and mountainous landscapes.

\section{Acknowledgements}

The authors express thanks for the basic information provided by the Urban and Rural Planning Bureau of Suining. Professors from Southwest University of Science and Technology contributed significantly to the selection and grade of evaluation indicators.

\section{References}

[1] Malczewski, J. (2004) GIS-Based Land-Use Suitability Analysis: A Critical Overview. Progress in Planning, 62, 3-65. https://doi.org/10.1016/j.progress.2003.09.002

[2] FAO (1993) Guidelines for Land-Use Planning.

[3] Liu, R., Zhang, K., Zhang, Z. and Borthwick, A.G.L. (2014) Land-Use Suitability Analysis for Urban Development in Beijing. Journal of Environmental Management, 145, 170-179. https://doi.org/10.1016/j.jenvman.2014.06.020

[4] Mou, L. (2015) Study on Land Suitability Evaluation. Cultural Geography, 16, 89-90.

[5] Comino, E., Bottero, M., Pomarico, S. and Rosso, M. (2014) Exploring the Environmental Value of Ecosystem Services for a River Basin through a Spatial Multicriteria Analysis. Land Use Policy, 36, 381-395.

https://doi.org/10.1016/j.landusepol.2013.09.006

[6] Reza, M.I.H., Abdullah, S.A., Nor, S.B.M. and Ismail, M.H. (2013) Integrating GIS and expert Judgment in a Multi-Criteria Analysis to Map and Develop a Habitat Suitability Index: A Case Study of Large Mammals on the Malayan Peninsula. Ecological Indicators, 34, 149-158. https://doi.org/10.1016/j.ecolind.2013.04.023

[7] Sieber, J. and Pons, M. (2015) Assessment of Urban Ecosystem Services Using Ecosystem Services Reviews and GIS-Based Tools. Procedia Engineering, 115, 53-60. https://doi.org/10.1016/j.proeng.2015.07.354

[8] Yu, Y. and Cheng, B. (2012) Study on Optimization Design of Driving Space with Land Saving Type. Anhui Architecture, 2, 51-52.

[9] Chen, D., Zhang, H. and Liu, H. (2016) Pursue the Truth, Devote to Education: 
Chen Hua-Kui, a Respectable Educator and Pioneer of China's Soil Microbiology. Protein Cell, 7, 389-390. https://doi.org/10.1007/s13238-016-0270-9

[10] Mitchell, D., Enemark, S. and van der Molen, P. (2015) Climate Resilient Urban Development: Why Responsible Land Governance Is Important. Land Use Policy, 48, 190-198. https://doi.org/10.1016/j.landusepol.2015.05.026

[11] Stefanucci, J.K., Proffitt, D.R., Banton, T. and Epstein, W. (2005) Distances Appear Different on Hills. Perception \& Psychophysics, 67, 1052-1060. https://doi.org/10.3758/BF03193631

[12] Zolekar, R.B. and Bhagat, V.S. (2015) Multi-Criteria Land Suitability Analysis for Agriculture in Hilly Zone: Remote Sensing and GIS Approach. Computers and Electronics in Agriculture, 118, 300-321. https://doi.org/10.1016/j.compag.2015.09.016

[13] Lin, G.C.S. and Ho, S.P.S. (2003) China's Land Resources and Land-Use Change: Insights from the 1996 Land Survey. Land Use Policy, 20, 87-107. https://doi.org/10.1016/S0264-8377(03)00007-3

[14] Zhang, Z., Sheng, L., Yang, J., Chen, X.A., Kong, L. and Wagan, B. (2015) Effects of Land Use and Slope Gradient on Soil Erosion in a Red Soil Hilly Watershed of Southern China. Sustainability, 7, 14309-14325. https://doi.org/10.3390/su71014309

[15] Wang, N., Zuo, X., Yang, Y. and Shao, Y. (2014) Study on Suitability Evaluation of Low Hill Slope Construction in Dali City Based on GIS. Journal of Anhui Agricultural Sciences, 42, 11512-11514.

[16] Li, W.S., Li, J.F. and Zhong, Z.L. (2014) GIS-Supported Evaluation of Ecological Suitability of Construction Land in Low-Slope Hilly Region of Chibi City, Hubei Province. Scientific and Technological Management of Land and Resources, 31, 1-4.

[17] Briassoulis, H. (2009) LAND USE, LAND COVER AND SOIL SCIENCE-Factors Influencing Land-Use and Land-Cover Change. Encyclopedia of Life Support Systems, I, 9.

[18] Wu, H.Y., Liu, Y. and Liu, X.H. (2015) Evaluating the Suitability of Construction Lands in Low-Slope Hilly Region Based on GIS: Taking Guangan County of Sichuan Province as an Example. Hubei Agricultural Sciences, No. 3, 555-559. 